\title{
Changing how we think about healthcare improvement
}

\author{
Complexity science offers ways to change our collective mindset about healthcare systems, \\ enabling us to improve performance that is otherwise stagnant, argues Jeffrey Braithwaite
}

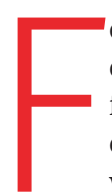

or all the talk about quality healthcare, systems performance has frozen in time. Only 50-60\% of care has been delivered in line with level 1 evidence or consensus based guidelines for at least a decade and a half $^{1-5}$; around a third of medicine is waste, with no measurable effects or justification for the considerable expenditure ${ }^{6-9}$; and the rate of adverse events across healthcare has remained at about one in 10 patients for 25 years. ${ }^{10-13}$ Dealing with this stagnation has proved remarkably difficult-so how do we tackle it in a new, effective way?

We need to understand why system-wide progress has been so elusive and to identify the kinds of initiatives that have made positive contributions to date. Then we can ask what new solutions are emerging that may make a difference in the future and start to change our thinking about healthcare systems.

\section{Why change is hard}

The overarching challenge lies in the nature of health systems. Healthcare is a complex

\section{KEY MESSAGES}

- The key measures of health system performance have frozen for decades $-60 \%$ of care is based on evidence or guidelines; the system wastes about $30 \%$ of all health expenditure; and some $10 \%$ of patients experience an adverse event

- Proponents of change too often use top down tools such as issuing more policy, prescribing more regulation, restructuring, and introducing more stringent performance indicators

- We must move instead towards a learning system that applies more nuanced systems thinking and provides stronger feedback loops to nudge systems behaviour out of equilibrium, thereby building momentum for change

- Effective change will need to factor in knowledge about the system's complexity rather than perpetuate the current improvement paradigm, which applies linear thinking in blunt ways

- Yet we should recognise how truly hard this is in the messy, real world of complex care adaptive system, meaning that the system's performance and behaviour changes over time and cannot be completely understood by simply knowing about the individual components. No other system is more complex: not banking, education, manufacturing, or the military. No other industry or sector has the equivalent range and breadth-such intricate funding models, the multiple moving parts, the complicated clients with diverse needs, and so many options and interventions for any one person's needs. Patient presentation is uncertain, and many clinical processes need to be individualised to each patient. Healthcare has numerous stakeholders, with different roles and interests, and uneven regulations that tightly control some matters and barely touch others. The various combinations of care, activities, events, interactions, and outcomes are, for all intents and purposes, infinite.

When advocates for improvement seek to implement change, health systems do not react predictably; they respond in different ways to the same inputs (staff, funding, presenting patients, buildings, and equipment). In the language of complexity science, this is "non-linearity." The sheer number of variables and the unpredictability of their interactions make it hard to impose order. And health systems are indeterministic-meaning that the future cannot be predicted by extrapolating from the past. They are also fractal and self similar, often looking alike in, for example, organisational culture in different places and at different points in time.

How then is a system as complex and seemingly dynamic as healthcare typically in a steady state, with entrenched behaviours, cultures, and politics? Because the total of the negotiations, trade-offs, and positioning of stakeholders pulls strongly towards inertia. ${ }^{1415}$ No one person or group is to blame; but a complex system clearly does not change merely because someone devises and then mandates a purpose designed solution. Studies of concerted improvement efforts, for example in North Carolina, USA, ${ }^{16}$ and in the NHS, ${ }^{17}$ show this. Instead, the system alters over time and to its own rhythm (idiosyncratically and locally). ${ }^{18}$

This raises further questions: what circumstances can precipitate changes in complex health systems, and what circumstances frustrate progress? Box 1 summarises selected initiatives. Attractors enable or create sufficient change for the system to be nudged before it settles into a

\section{Box 1: Selected attractors and repellents of change}

\section{Systems can change when:}

- Stimulated by medical progress-eg, new diagnostic tests and treatments, imaging technology, or surgical advances

- Incontrovertible evidence shows public benefit-eg, immunising infants or reducing smoking rates in developed countries

- New models of care emerge-eg, the shift to day only surgery or providing GP advice remotely via apps, teleconferences, or telemedicine

- Clinical practices alter by necessity or because of professional acceptance-eg, laparoscopic techniques

- Sources: Thimbleby, $2013^{19}$; Farmanova et al, $2016^{20}$; Westerlund et al, $2015^{21}$; Watt et al, $2017^{22}$

Systems can reject change when:

- The primary or sole strategy is to mandate solutions from the top down

- The change is not supported by parties with power to resist or reject, such as the medical profession or the media

- The initiative encounters entrenched bureaucracy, particularly in organisations such as public hospitals

- More policies and procedures are issued on top of a multiplicity of existing policies and procedures

- Attempts to alter deep seated politics or cultures are superficial

- Sources: Coiera, $2011^{15}$; Braithwaite et al, $2017^{23}$; Khalifa, $2013^{24}$ 


\section{Box 2: Initiatives to change the system's hardware}

- Restructuring organisations-The boxes on the NHS organisation chart have regularly been redrawn to little benefit. Although such reorganisations do produce structural change, they do not greatly alter entrenched cultures, much less downstream clinical outcomes. ${ }^{25}$ Two studies assessing structural change showed that merging NHS trusts $^{26}$ and restructuring Australian hospitals ${ }^{27}$ produced no measurable gains and put things back by 18 months or more.

- Capital investments-New buildings and new equipment or technology are necessary changes that can contribute to better, more modernised models of caring. Technology supporting new diagnoses and treatments, tests, and clinical techniques can instigate important gains. These initiatives, however, are mostly left to research and development departments, researchers, or clinicians, while politicians and managers focus on organisational charts, opening new hospitals, and prescribing policy.

- Financial models and targets-Studies from the US Commonwealth Fund and international experience indicate that no one financial model is better than any other, ${ }^{28}$ ${ }^{29}$ and perverse outcomes and gaming often result from imposed targets and key performance indicators. ${ }^{30}$

new state. Resisters or repellents hold the status quo or reject change.

A key message from the examples in box 1 is that change is accepted when people are involved in the decisions and activities that affect them, but they resist when change is imposed by others. Policy mandated change is never given the same weight as clinically driven change.

\section{Systems hardware and software}

Much has been written about the many efforts to initiate change in health systems around the world, most of which seems to presuppose two familiar pathways. One is to alter the system's "hardware" by restructuring the organisation chart, upgrading the infrastructure, or changing financial models or targets, for example (box 2). The NHS and other systems have invested heavily in many such efforts. But the gains have been modest, and the extent to which such changes have contributed to better patient care is unclear. The other approach is to change the "software" of the system by tackling the culture of clinical settings (and the quality of leadership offered by managers and policy makers) and using implementation and improvement methods (box 3).

\section{Changing our collective mindset}

Instead of using the metaphor of hardware and software, we could change our thinking. We need to recognise three problems. Firstly, implementing and securing acceptance of new solutions is difficult, even when armed with level 1 or other persuasive evidence-this is the take-up problem. Secondly, disseminating knowledge of an intervention's benefits across the entire system is hard-this is the diffusion problem. Thirdly, even if a new model of care, technology, or practice is successfully taken up and widely spread, its shelf life will be short-this is the sustainability problem. The pace at which new ideas are being generated, and previous ones discarded, is accelerating, particularly so over the past 20 years.

So paradoxically, although nothing lasts, genuine transformational improvement remains frustratingly elusive. Adding to the challenge, as Contandriopoulos and colleagues remind us, knowledge (even level 1 evidence) is unevenly distributed, poorly understood, and always contested. ${ }^{38}$

Accepting this reality is uncomfortable for those promoting improvement. "Agents

Box 3: Initiatives to change the system's software

- Enhancing organisational and workplace culture-A systematic review found a consistent association in over 62 studies between organisational and workplace cultures and patient outcomes across multiple settings. ${ }^{31}$ Encouraging positive organisational cultures to promote better patient outcomes seems time well spent. But these are localised solutions.

- Implementation science and improvement studies-Studies have tested models for creating implementable interventions and for getting more research evidence into routine clinical practice. ${ }^{32}{ }^{33}$ Ideas have emerged-such as the PARiHS framework ${ }^{34}$ and models that take a more system-wide view ${ }^{32}-$ that identify important ingredients in change such as context, persuasiveness of the evidence, and active facilitation. But applying such models to systems has shown the limits of progress. For any intervention, the effect size that can be secured when successful (and many interventions yield no or little benefit) is modest; perhaps around $16 \%$ on average. ${ }^{35-37}$

of change" tend to prefer optimism or even the delusion that their new policies or initiatives are widely adopted. ${ }^{14}$ This dichotomy has been described as "work-asimagined" by policy makers and managers and as "work-as-done" by the clinicians at the coalface. ${ }^{39}$ Policy makers and managers try to instigate change remotely; clinicians try to deliver care proximally. This leads to much antagonism-or merely ignorance of the other's role.

\section{Understanding emergence and resilience}

How do we move forward? Whatever solutions we choose must reflect the complexity of the system and respect its resilient features. ${ }^{40}$ We must change our approach to understanding health systems and their intricacies. $^{4142}$

One way is to break with the NHS's pattern of attempting systems improvement from the top down. Complex adaptive systems have multiple interacting agents with degrees of discretion to repel, ignore, modify, or selectively adopt top down mandates. Clinicians behave how they think they should, learning from and influencing each other, rather than by responding to managers' or policy makers' admonitions. Frontline clinicians in complex adaptive systems accept new ideas based on their own logic, not that of those in the upper echelons. Healthcare is governed far more by local organisational cultures and politics than by what the secretary of state for health or a remote policy maker or manager wants.

Change, when it does occur, is always emergent. This is when features of the system, and behaviours, appear unexpectedly, arising from the interactions of smaller or simpler entities; thus, unique team behaviours emerge from individuals and their interactions.

Those on the frontline of care (clinicians, staff, patients) navigate change through their small part of the system, adjusting to their local circumstances, and responding to their own interests rather than to top down instructions. Thus, healthcare is naturally resilient, always buffering itself against change that does not make sense to those who are on the ground, delivering care.

\section{Towards a nuanced appreciation of change?}

Here are six principles on which a new approach to change might be built. Firstly, we must pay much more attention to how care is delivered at the coalface. Bureaucrats and managers, among others, will not improve the system or make patients safer by issuing swathes more policy, regulating more avidly, introducing more clunky IT systems, or striking off doctors. ${ }^{43}$ 


\begin{tabular}{|c|c|}
\hline Enabler (what to do) & Insight (why to do it) \\
\hline \multicolumn{2}{|l|}{ For policy makers: } \\
\hline Take multiple evaluations of what's going on & Different stakeholders have distinguishable views on what's happening in complex systems \\
\hline Use system tools to uncover the system's features & $\begin{array}{l}\text { Causal loop diagrams, social network analyses, role plays, and simulation can provide insights into a system's } \\
\text { characteristics }\end{array}$ \\
\hline Customise change to local contexts & Culture is unique to the context: tailoring change to the circumstances is crucial \\
\hline Work with, not against, trends & Going against the currents of change is possible, but is fraught with frustration and risk-the trend is your friend \\
\hline Balance standardisation and variety & There is constant tension between the push for uniformity and the need for local initiatives \\
\hline Use the informal system, not just the formal system & Organisational chart thinking only gets people so far; use the informal system and its cultural and political attributes \\
\hline $\begin{array}{l}\text { Take every opportunity to bolster communication, trust, and } \\
\text { interpersonal relations }\end{array}$ & $\begin{array}{l}\text { Care is delivered as a system of systems, with multiple interacting networks of people at its heart-communication, trust, } \\
\text { and relationships are key to any progress }\end{array}$ \\
\hline \multicolumn{2}{|l|}{ For managers and improvement teams: } \\
\hline Model the system's properties & Systems diagrams and models, computer based or hand drawn, can illuminate the dynamics of the system \\
\hline Use multimethod research and improvement techniques & $\begin{array}{l}\text { Randomised controlled trials or single method data gathering approaches rarely expose sufficient dimensions of complex } \\
\text { problems }\end{array}$ \\
\hline Appreciate less is more in interventions & $\begin{array}{l}\text { Resist aiming to control the system through improvement strategies, projects, and change initiatives: spend more time } \\
\text { learning about the effects of interventions than obsessing about intricate designs }\end{array}$ \\
\hline Leverage complexity thinking & Immerse local teams in complexity science and systems thinking \\
\hline Focus less on the individual and more on the system & It's much harder to change individuals_-seek instead to nudge or perturb the system \\
\hline $\begin{array}{l}\text { Develop and apply feedback to people involved at every } \\
\text { opportunity }\end{array}$ & Change and improvement is a set of feedback loops, not an event or a linear process \\
\hline Look for things going right as well as those going wrong & This promotes a more balanced view of the system \\
\hline \multicolumn{2}{|l|}{ For frontline clinicians: } \\
\hline $\begin{array}{l}\text { Adopt a new problem solving focus based on systems thinking } \\
\text { rather than obsessing with finding "a" way forward }\end{array}$ & Search for interconnections rather than getting stuck on any one solution \\
\hline $\begin{array}{l}\text { Look for behavioural patterns in the system and listen to the } \\
\text { language people use }\end{array}$ & $\begin{array}{l}\text { The rich behaviours and practices of others, and the signals and messages they convey, are full of beneficial cultural and } \\
\text { systems information }\end{array}$ \\
\hline Beware excessively causal logic & Take care in attributing cause and effect-overgeneralising causation is a common error \\
\hline $\begin{array}{l}\text { Trade-off between constant turmoil and implementing changes } \\
\text { before they are ready }\end{array}$ & $\begin{array}{l}\text { All systems sit not far from the edge of chaos: ride the boundary, and remember the old lesson that much in clinical } \\
\text { practice and systems is uncertain }\end{array}$ \\
\hline Understand that adaptation is almost always micro and granular & Big picture transformational change is rare and is expressed differently in different settings when it does occur \\
\hline Appreciate that humans have a social brain & $\begin{array}{l}\text { Organisational participants are perennially tuned in to the behavioural repertoires of others: use this expertise, and be } \\
\text { attentive to others' needs and motivations }\end{array}$ \\
\hline
\end{tabular}

Secondly, all meaningful improvement is local, centred on natural networks of clinicians and patients. ${ }^{44}$ One size fits all templates of change, represented by standardisation and generic strategies, too often fail. We must encourage ideas from many sources; care processes and outcomes will vary whatever we do.

Thirdly, we must acknowledge that clinicians doing complex everyday work get things right far more than they get them wrong. We focus on the $10 \%$ of adverse events while mostly overlooking the $90 \%$ of care that has no harm..$^{40}$ Understanding errors is critical, as is seeking to stop outmoded, wasteful, or excessive care. But, if we also better appreciate how clinicians handle dynamic situations throughout the day, constantly adapting, and getting so much right, we can begin to identify the factors and conditions that underpin that success.

This leads to a fourth, related, point. A recent book ${ }^{45}$ looking at achievements in healthcare delivery across 60 low, middle, and high income countries showed us that every system can tell multiple success stories. These range from organ donation and transplantation in Spain to early warning systems for deteriorating patients in Australia and Qatar, implementing minimum required standards in Afghanistan, making improvements in information technology in Taiwan, and embracing community based health insurance in Rwanda. These apparently disparate achievements have four common factors: begin with small scale initiatives and build up; convert data and information into intelligence and give this openly to the appropriate decision makers; remember the lone hero model does not work and that collaboration underpins all productive change; and always start with the patient at the centre of any reform measure. ${ }^{46}$ Such inspiring ideas reflect complexity thinking and are not necessarily predicated on reductionist, cause-effect logic.

Fifthly, we could simply be more humble in our aspirations. Putting the myth of inevitable progress aside, we should recognise that big, at-scale interventions sometimes have little or no effects and that small initiatives can sometimes yield unanticipated outcomes. ${ }^{47}$ We must admit to ourselves that we cannot know in advance which will occur.

Sixthly, and most importantly, we might adopt a new mental model that appreciates the complexity of care systems and understands that change is always unpredictable, hard won, and takes time, it is often tortuous, and always needs to be tailored to the setting. Table 1 shows 20 ways to exploit these principles. These enablers and insights need practice but can be used by anyone, including patients. For ease of application, they have been separated into complexity approaches for policy makers, managers and improvement teams, and frontline clinicians.

\section{Conclusion}

We need to turn healthcare into a learning system, with participants attuned to systems features and with strong feedback loops to try to build momentum for change. If we construct a shared outlook and draw on new thinking paradigms, perhaps we can move beyond today's frozen systems performance. A final note of caution goes to the proponents of today's most popular strategies: it's time to stop thickening the rule book, reorganising the boxes on the organisation chart, and introducing more key performance indicators-and to do something more sophisticated.

Contributorship statement: JB is the sole contributor and author.

Competing interests: I have read and understood BMJ policy on declaration of interests and declare there are no competing interests in association with this manuscript.

Provenance and peer review: Commissioned; externally peer reviewed.

This article is one of a series commissioned by The $B M J$ based on ideas generated by a joint editorial group with members from the Health Foundation and The BMJ, including a patient/carer. The 
$B M J$ retained full editorial control over external peer review, editing, and publication. Open access fees and The BMJ's quality improvement editor post are funded by the Health Foundation.

This is an Open Access article distributed in accordance with the terms of the Creative Commons Attribution (CC BY 4.0) license, which permits others to distribute, remix, adapt and build upon this work, for commercial use, provided the original work is properly cited. See: http://creativecommons.org/ licenses/by/4.0/.

\section{Jeffrey Braithwaite, professor}

${ }^{1}$ Macquarie University, Australian Institute of Health Innovation, Level 6, 75 Talavera Road North Ryde, NSW 2109, Australia

\section{Correspondence to: J Braithwaite}

jeffrey.braithwaite@mq.edu.au

1 Braithwaite J, Hibbert PD, Jaffe A, et al. Quality of health care for children in Australia, 20122013. JAMA 2018;319:1113-24. doi:10.1001/ jama.2018.0162

2 Mangione-Smith R, DeCristofaro AH, Setodji CM, et al. The quality of ambulatory care delivered to children in the United States. N Engl I Med 2007;357:151523. doi:10.1056/NEJMsa064637

3 McGlynn EA, Asch SM, Adams J, et al. The quality of health care delivered to adults in the United States. N Engl/ Med 2003;348:2635-45. doi:10.1056/ NEJMsa022615

4 Runciman WB, Hunt TD, Hannaford NA, et al. CareTrack: assessing the appropriateness of health care delivery in Australia. Med J Aust 2012;197: 100-5. doi:10.5694/mja12.10510

5 Braithwaite J, Donaldson L. Patient safety and quality. In: Ferlie E, Montgomery K, Reff A, eds. The Oxford Handbook of Health Care Management. Oxford University Press, 2016: 325-51.

6 Berwick DM, Hackbarth AD. Eliminating waste in US health care. JAMA 2012;307:1513-6. doi:10.1001/ jama.2012.362

7 OECD. Tackling wasteful spending on health. OECD Publishing, 2017.

8 Saini V, Brownlee S, Elshaug AG, Glasziou P, Heath I. Addressing overuse and underuse around the world. Lancet 2017;390:105-7. doi:10.1016/S01406736(16)32573-9

9 Saini V, Garcia-Armesto S, Klemperer D, et al. Drivers of poor medical care. Lancet 2017;390:178-90. doi:10.1016/S0140-6736(16)30947-3

10 Baker GR, Norton PG, Flintoft V, et al. The Canadian Adverse Events Study: the incidence of adverse events among hospital patients in Canada. CMAJ 2004;170:1678-86. doi:10.1503/ cmaj.1040498

11 Brennan TA, Leape LL, Laird NM, et al. Incidence of adverse events and negligence in hospitalized patients. Results of the Harvard Medical Practice Study I. N Engl J Med 1991;324:370-6. doi:10.1056/NEJM199102073240604

12 Vincent C, Neale G, Woloshynowych M. Adverse events in British hospitals: preliminary retrospective record review. BMJ 2001;322:517-9. doi:10.1136/ bmj.322.7285.517

13 Wilson RM, Runciman WB, Gibberd RW, Harrison BT Newby L, Hamilton JD. The quality in Australian health care study. Med I Aust 1995;163:458-71.

14 Braithwaite J. The medical miracles delusion. J R Soc Med 2014;107:92-3. doi:10.1177/0141076814523951

15 Coiera E. Why system inertia makes health reform so difficult. BMJ 2011;342:d3693. doi:10.1136/ bmj.d3693

16 Landrigan CP, Parry GJ, Bones CB, Hackbarth AD, Goldmann DA, Sharek PJ. Temporal trends in rates of patient harm resulting from medical care. $N$ Engl J Med 2010;363:2124-34. doi:10.1056/ NEJMsa1004404

17 Benning A, Dixon-Woods M, Nwulu U, et al. Multiple component patient safety intervention in English hospitals: controlled evaluation of second phase. BMJ 2011;342:d199. doi:10.1136/bmj.d199
18 Sturmberg JP, O'Halloran DM, Martin CM. Understanding health system reform - a complex adaptive systems perspective. J Eval Clin Pract 2012;18:202-8. doi:10.1111/j.13652753.2011.01792x

19 Thimbleby H. Technology and the future of healthcare. J Public Health Res 2013;2:e28. doi:10.4081/jphr.2013.e28

20 Farmanova E, Kirvan C, Verma J, et al. Triple Aim in Canada: developing capacity to lead to better health, care and cost. Int I Qual Health Care 2016:28:830-7.

21 Westerlund A, Garvare R, Höög E, et al. Facilitating system-wide organizational change in health care. Int I Qual Serv Sci 2015;7:

72-8910.1108/IJQSS-01-2015-0004.

22 Watt N, Sigfrid L, Legido-Quigley H, et al. Health systems facilitators and barriers to the integration of HIV and chronic disease services: a systematic review. Health Policy Plan. 2017;32(suppl_4):iv13-iv26.

23 Braithwaite J, Westbrook J, Coiera E, et al. A systems science perspective on the capacity for change in public hospitals. Isr J Health Policy Res 2017;6:16 doi:10.1186/s13584-017-0143-6

24 Khalifa M. Barriers to health information systems and electronic medical records implementation: a field study of Saudi Arabian hospitals. Procedia Comput Sci 2013;21:335-4210.1016/j. procs.2013.09.044.

25 Fitzgerald L, McDermott A. Challenging Perspectives on Organizational Change in Health Care. Routledge, 2017.

26 Fulop N, Protopsaltis G, Hutchings A, et al. Process and impact of mergers of NHS trusts: multicentre case study and management cost analysis. BM/ 2002;325:246. doi:10.1136/ bmj.325.7358.246

27 Braithwaite J, Westbrook MT, Hindle D, ledema RA, Black DA. Does restructuring hospitals result in greater efficiency? An empirical test using diachronic data. Health Serv Manage Res 2006;19:1-12 doi:10.1258/095148406775322016

28 Ryan AM, Krinsky S, Kontopantelis E, Doran T. Longterm evidence for the effect of pay-for-performance in primary care on mortality in the UK: a population study. Lancet 2016;388:268-74. doi:10.1016/ S0140-6736(16)00276-2

29 The Commonwealth Fund. Retrieved from: http:// www.commonwealthfund.org.

30 Mannion R, Braithwaite J. Unintended consequences of performance measurement in healthcare: 20 salutary lessons from the English National Health Service. Intern Med / 2012;42:569-74. doi:10.1111/j.1445-5994.2012.02766.x

31 Braithwaite J, Herkes J, Ludlow K, Testa L, Lamprell G. Association between organisational and workplace cultures, and patient outcomes: systematic review. BMJ Open 2017;7:e017708. doi:10.1136/ bmjopen-2017-017708

32 Kitson A, Brook A, Harvey G, et al. Using complexity and network concepts to inform healthcare knowledge translation. Int J Health Policy Manag 2017;7:231-43. doi:10.15171/ ijhpm.2017.79

33 Rapport F, Clay-Williams R, Churruca K, et al. The struggle of translating science into action: foundational concepts of implementation science. I Eval Clin Prac, 2017, 10.1111/jep.12741.

34 Kitson A, Harvey G, McCormack B. Enabling the implementation of evidence based practice: a conceptual framework. Qual Health Care 1998;7:149-58. doi:10.1136/qshc.7.3.149

35 Grimshaw J, Eccles M, Thomas R, et al. Toward evidence-based quality improvement. Evidence (and its limitations) of the effectiveness of guideline dissemination and implementation strategies 1966 1998. J Gen Intern Med 2006;21(Suppl 2):S14-20.

36 Grimshaw IM, Eccles MP, Lavis JN, Hill SI, Squires JE. Knowledge translation of research findings. Implement Sci 2012;7:50. doi:10.1186/17485908-7-50

37 Grimshaw JM, Thomas RE, MacLennan G, et al. Effectiveness and efficiency of guideline dissemination and implementation strategies. Health Technol Assess 2004;8:iii-iv, 1-72. doi:10.3310/ hta8060

38 Contandriopoulos D, Lemire M, Denis JL, Tremblay E. Knowledge exchange processes in organizations and policy arenas: a narrative systematic review of the literature. Milbank Q 2010;88:444-83. doi:10.1111/j.1468-0009.2010.00608.x

39 Braithwaite J, Wears RL, Hollnagel E, eds. Reconciling Work-as-Imagined and Work-as-Done. Vol 3. Abingdon, UK: Taylor \& Francis, 2017. (Resilient Health Care.).

40 Hollnagel E, Braithwaite J, Wears R, eds. Resilient Health Care. Ashgate, 2013

41 Braithwaite J, Churruca K, Ellis LA, et al. Complexity science in healthcare - aspirations, approaches, applications and accomplishments: a white paper. Sydney, Australia: Australian Institute of Health Innovation, Macquarie University; 2017.

42 Braithwaite J, Wears RL, Hollnagel E. Resilient health care: turning patient safety on its head. Int J Qual Health Care 2015;27:418-20. doi:10.1093/intahc/ mzv063

43 Dyer C. Bawa-Garba case has left profession shaken and stirred. BMJ 2018;360:k456. doi:10.1136/ bmj.k456

44 Braithwaite J, Runciman WB, Merry AF. Towards safer, better healthcare: harnessing the natural properties of complex sociotechnical systems. Qual Saf Health Care 2009;18:37-41. doi:10.1136/ qshc.2007.023317

45 Braithwaite J, Mannion R, Matsuyama Y, et al, eds. Health Systems Improvement Across the Globe. Success Stories from 60 Countries. CRC Press Taylor and Francis Group, 2017

46 Braithwaite J, Mannion R, Matsuyama Y, et al. Accomplishing reform: successful case studies drawn from the health systems of 60 countries. Int J Qual Health Care 2017;29:880-6. doi:10.1093/intqhc/ mzx122

47 Rickles D, Hawe P, Shiell A. A simple guide to chaos and complexity. J Epidemiol Community Health 2007;61:933-7. doi:10.1136/ jech.2006.054254

48 Plsek PE, Greenhalgh T. Complexity science: The challenge of complexity in health care. BMJ 2001;323:625-8. doi:10.1136/ bmj.323.7313.625

49 Plsek PE, Wilson T. Complexity, leadership, and management in healthcare organisations. BMJ 2001;323:746-9. doi:10.1136/ bmj.323.7315.746

50 Leykum LK, Lanham HJ, Pugh JA, et al. Manifestations and implications of uncertainty for improving healthcare systems: an analysis of observational and interventional studies grounded in complexity science. Implement Sci 2014;9:165. doi:10.1186 s13012-014-0165-1

51 Greenhalgh T, Stones R. Theorising big IT programmes in healthcare: strong structuration theory meets actor-network theory. Soc Sci Med 2010;70:1285-94. doi:10.1016/j. socscimed.2009.12.034

52 Greenhalgh T. Higher education governance as language games: a wittgensteinian case study of the breakdown of governance at the London School of Economics 2004-2011. High Educ Q 2015;69:19321310.1111/hequ.12064

53 Greenhalgh T, Shaw S, Wherton J, et al. SCALS: a fourth-generation study of assisted living technologies in their organisational, social, political and policy context. BMJ Open 2016;6:e010208 doi:10.1136/bmjopen-2015-010208

54 Bar-Yam Y. Improving the effectiveness of health care and public health: a multiscale complex systems analysis. Am J Public Health 2006;96:459-66. doi:10.2105/AJPH.2005.064444

55 May CR, Johnson M, Finch T. Implementation, context and complexity. Implement Sci 2016;11:141. doi:10.1186/s13012-016-0506-3

56 Axelrod R, Cohen MD. Harnessing Complexity. Organizational Implications of a Scientific Frontier. Basic Books, 2001. 
OPEN ACCESS

This is an Open Access article distributed in accordance with the terms of the Creative Commons Attribution (CC BY 4.0) license, which permits others to distribute, remix, adapt and build upon this work, for commercial use, provided the original work is properly cited. See: http:// creativecommons.org/licenses/by/4.0/. 